УДК [615.451.16.012:582.794.1].074.015.11

\title{
ФИТОХИМИЧЕСКОЕ ИЗУЧЕНИЕ И ОЦЕНКА ФАРМАКОЛОГИЧЕСКОЙ АКТИВНОСТИ ВОДНЫХ ИЗВЛЕЧЕНИЙ ТРАВЫ СЕЛЬДЕРЕЯ ПАХУЧЕГО
}

\author{
() И.В. Пиукова", С.А. Кулешова \\ Пятигорский фрилиал Волгоградского государственного медицинского \\ университета, пр. Калинина, 11, Пятигорск 357532 (Россия), \\ e-mail:daironas@mail.ru
}

Приведены сведения об изучении состава травы сельдерея пахучего (Apium graveolens L.), произрастающего на Ceверном Кавказе, и исследовании фармакологической активности его водных извлечений. Установлено, что настой и отвар травы сельдерея пахучего обладают мочегонным и желчегонным действием и являются практически нетоксичными.

Ключевые слова: сельдерей, Apium graveolens L., биологически активные соединения.

\section{Введение}

Сельдерей пахучий (культурный) - Apium graveolens L. относится к семейству сельдерейные (Apiaceae) или зонтичные (Umbelliferae). Родина сельдерея - Южная Европа, Средиземноморье. В культуре сельдерей пахучий распространен в Европе, Северной и Центральной Америке. Специально в целях получения эфирного масла его культивируют в Индии, Китае, Венгрии, Голландии и США. В нашей стране сельдерей повсеместно выращивается в виде корнеплодных сортов и как огородное растение. Существует три основных разновидности сельдерея: Apium graveolens secalinum - листовой сельдерей (отрывной сельдерей); A. graveolens dulce - черешковый сельдерей (стебли сельдерея); A. graveolens rapaceum - корневой сельдерей (корень сельдерея). Сельдерей пахучий (культурный) (Apium graveolens L.) является разновидностью листового сельдерея. Листовой сельдерей не образует корнеплодов. Листья сельдерея имеют характерный для этого растения резкий и терпкий (пряный) аромат. У листового сельдерея нет развитого корнеплода и толстых черешков, зато листья богаты витаминами.

Сельдерей - одно из древнейших культурных растений. Его знали еще во II в. до н.э., изображали на монетах древней Греции, Сицилии. Древние греки высоко ценили и лечебные свойства этого растения. Они использовали сельдерей для лечения болезней внутренних органов, включали в состав различных лекарственных средств. В Средние века сельдерей был одним из важнейших лекарственных растений для лечения заболеваний почек, печени, крови, суставов.

В народной медицине Северного Кавказа сельдерей пахучий используют как диуретическое, стимулирующее центральную нервную систему, желчегонное, противоцинготное средство. Также сельдерей применяют при альбуминурии, бронхиальной астме, респираторных заболеваниях, метеоризме. Предложено использовать стабилизированный сок в качестве диуретического средства [1]. Изучены антиоксидантные свойства надземной части сельдерея [2].

Сельдерей пахучий широко распространен в регионе, относится к лекарственным растениям, однако химический состав изучен недостаточно, слабо освещен в литературе и поэтому нуждается в дополнительном исследовании. Из данных литературы известно, что химический состав травы сельдерея пахучего

Пшукова Ирина Васильевна - старший преподаватель кафедры фармакогнозии, кандидат фармацевтических наук, e-mail: daironas@mail.ru

Кулешова Светлана Анатольевна - доцент кафедры фармакогнозии, кандидат фармацевтических наук, e-mail: daironas@mail.ru представлен различными классами соединений. Приведены сведения о составе эфирного масла корней, надземной части растения $[1,2]$.

Цель работы - изучение химического состава надземной части сельдерея пахучего и исследование фармакологической активности ее настоя и отвара.

\footnotetext{
*Автор, с которым следует вести переписку.
} 


\section{Экспериментальная часть}

В качестве исходного сырья использовали траву сельдерея пахучего, заготовленную на Северном Кавказе в период цветения (июнь-июль; август-сентябрь).

Для изучения состава фенольных соединений использовали хроматографический метод. 5,0 г измельченной до 1-2 мм сухой травы сельдерея пахучего экстрагировали спиртом этиловым $70 \%$ до полного истощения сырья. Объединенное извлечение упаривали под вакуумом до водного остатка, охлаждали, фильтровали. Фильтрат использовали для жидкостной экстракции органическими растворителями: хлороформом, этилацетатом, бутанолом. Водный остаток спирто-водных извлечений переносили в делительную воронку и взбалтывали с равными объемами хлороформа. После разделения слоев органический растворитель отделяли. Указанную процедуру проводили 7-8 раз. Хлороформные извлечения объединяли. Водный остаток после экстракции хлороформом нагревали на водяной бане для удаления хлороформа, охлаждали и обрабатывали этилацетатом. Водный остаток после экстракции этилацетатом нагревали на водяной бане для удаления этилацетата, охлаждали и обрабатывали бутанолом. Полученные с помощью органических растворителей извлечения упаривали в вакууме до смолообразного остатка и использовали для проведения хроматографического анализа.

Наличие флавоноидов определяли в этилацетатных фракциях и в водном остатке извлечения из травы сельдерея пахучего с помощью характерных качественных реакций (цианидиновой пробы и цианидиновой пробы по Брианту, с 2\% спиртовым раствором алюминия хлорида). Положительные реакции свидетельствовали о присутствии флавоноидов в исследуемом сырье. Реакция комплексообразования с алюминия хлоридом в среде $70 \%$ спирта этилового положена в основу количественного определения суммы флавоноидов.

Хроматографией этилацетатной фракции на бумаге с использованием специфических реактивов обнаруживали флавоноиды. Хроматограммы просматривали в УФ-свете до и после обработки хромогенными реактивами [3]. В результате анализа обнаружено 5 соединений с $R_{\mathrm{f}} 0,12, \mathrm{R}_{\mathrm{f}} 0,18, \mathrm{R}_{\mathrm{f}} 0,22, \mathrm{R}_{\mathrm{f}} 0,25, \mathrm{R}_{\mathrm{f}} 0,36$.

Определение кумаринов проводили хроматографированием хлороформных фракций в тонком слое сорбента на пластинках «Silufol».

Для обнаружения фенолкарбоновых кислот использовали этилацетатную фракцию. Определение проводили хроматографированием на бумаге в системе растворителей с последующей обработкой хроматограмм специфическими реактивами. Хроматограммы просматривали в видимом и УФ-свете до и после обработки реактивами [4]. В результате анализа обнаружено 2 соединения с $\mathrm{R}_{\mathrm{f}} 0,26, \mathrm{R}_{\mathrm{f}} 0,33$.

В водных извлечениях сырья методом тонкослойной хроматографии на пластинках «Silufol» определяли органические кислоты [5]. Результаты идентификации биологически активных соединений (БАС) в траве сельдерея пахучего методом хроматографии представлены в таблице 1.

Таблица 1. Результаты идентификации биологически активных соединений (БАС) в траве сельдерея пахучего методом хроматографии

\begin{tabular}{|c|c|c|c|}
\hline $\begin{array}{c}\text { Определяемый } \\
\text { класс БАС }\end{array}$ & Система растворителей & Детектирование & Результат \\
\hline Флавоноиды & 30\% уксусная кислота & $\begin{array}{c}\text { пары аммиака, спиртовый раствор } \\
\text { щелочи, } 2 \% \text { метанольный раствор } \\
\text { циркония хлорокиси }\end{array}$ & $\begin{array}{c}\text { свечение пятен желтого, } \\
\text { темно-желтого, желто- } \\
\text { зеленого, оранжевого, } \\
\text { буро-желтого и темно- } \\
\text { коричневого цвета }\end{array}$ \\
\hline $\begin{array}{c}\text { Фенолкарбоновые } \\
\text { кислоты }\end{array}$ & $2 \%$ уксусная кислота & $\begin{array}{c}\text { пары аммимака, } 0,5 \% \text { спиртовый } \\
\text { раствор бромкрезолового зеленого, } \\
1 \% \text { спиртовый раствор хлорида } \\
\text { окисного железа (III), диазотиро- } \\
\text { ванный } n \text {-нитроанилин }\end{array}$ & $\begin{array}{c}\text { свечение пятен } \\
\text { зеленовато-голубого } \\
\text { цвета }\end{array}$ \\
\hline Кумарины & $\begin{array}{c}\text { Бензол - этилацетат }(2: 1) \text {; } \\
\text { петролейный эфир - диэти- } \\
\text { ловый эфир }(10: 3,5)\end{array}$ & $\begin{array}{c}\text { пары аммиака, } 10 \% \text { спиртовый рас- } \\
\text { твор гидроксида калия, } 10 \% \text { раствор } \\
\text { диазотированной сульфаниловой } \\
\text { кислоты }\end{array}$ & $\begin{array}{c}\text { свечение пятен } \\
\text { фиолетового цвета }\end{array}$ \\
\hline $\begin{array}{l}\text { Органические } \\
\text { кислоты }\end{array}$ & $\begin{array}{c}\text { смесь 95\% этилового спир- } \\
\text { та и концентрированного } \\
\text { раствора аммиака }(16: 4,5)\end{array}$ & $\begin{array}{c}\text { 0,1\% спиртовый раствор бромкре- } \\
\text { золового зеленого }\end{array}$ & $\begin{array}{c}\text { ярко-желтые пятна } \\
\text { на голубом фоне }\end{array}$ \\
\hline
\end{tabular}


В водных извлечениях из травы сельдерея пахучего определяли дубильные вещества, углеводы. Наличие дубильных веществ установили с помощью качественных реакций: с раствором желатина, с $1 \%$ раствором хинина, с железоаммонийными квасцами, с формальдегидом и хлористоводородной кислотой.

Полисахариды при добавлении 96\% этилового спирта к концентрированному водному извлечению выпадали в осадок. Для дальнейшего исследования полисахаридный комплекс извлекали горячей водой, водные извлечения концентрировали и полисахариды осаждали 95\% этиловым спиртом. Осадок отфильтровывали, промывали органическими растворителями, высушивали [6-8].

Проведена количественная оценка травы сельдерея пахучего по содержанию БАС (табл. 2) [6-9].

Таблица 2. Количественное содержание биологически активных соединений в траве сельдерея пахучего

\begin{tabular}{|c|c|c|c|c|c|c|}
\hline \multirow{2}{*}{ Класс БАС } & \multirow{2}{*}{$\begin{array}{c}\text { Найдено в среднем, } \\
\text { X, \% }\end{array}$} & \multirow{2}{*}{$\begin{array}{c}\text { Метод количествен- } \\
\text { ного определения }\end{array}$} & \multicolumn{4}{|c|}{ Метрологические характеристики } \\
\hline & & & $\mathrm{S}$ & $\mathrm{S}_{\mathrm{x}}$ & $\Delta \mathrm{x}$ & $\varepsilon \%$ \\
\hline Флавоноиды & $\begin{array}{c}0,73 \\
\text { (в пересчете } \\
\text { на кверцетин) }\end{array}$ & $\begin{array}{l}\text { Дифференциальная } \\
\text { спектрофотометрия }\end{array}$ & 0,0316 & 0,0129 & 0,0309 & 1,78 \\
\hline $\begin{array}{c}\text { Органические } \\
\text { кислоты }\end{array}$ & $\begin{array}{c}3,43 \\
\text { (в пересчете } \\
\text { на яблочную кислоту) }\end{array}$ & Титриметрия & 0,0403 & 0,0020 & 0,0137 & 0,93 \\
\hline $\begin{array}{c}\text { Аскорбиновая } \\
\text { кислота }\end{array}$ & 0,26 & Титриметрия & 0,0501 & 0,0025 & 0,0200 & 1,25 \\
\hline $\begin{array}{c}\text { Дубильные } \\
\text { вещества }\end{array}$ & 12,44 & Титриметрия & 0,1035 & 0,0422 & 0,0110 & 0,87 \\
\hline Полисахариды & 6,3 & Гравиметрия & 0,0153 & 0,0063 & 0,0210 & 0,78 \\
\hline
\end{tabular}

\section{Обсуждение результатов}

После проведенных исследований установлено, что трава сельдерея пахучего, произрастающего на Северном Кавказе, содержит фенольные соединения: флавоноиды, кумарины, фенолкарбоновые кислоты, дубильные вещества. При исследовании компонентного состава методом бумажной хроматографии в качестве «свидетелей» использовались РСО флавоноидов и фенолкарбоновых кислот. В результате доказано наличие в траве сельдерея пахучего не менее 5 флавоноидов (рутин, апигенин, лютеолин, гиперазид и кверцетин), 2 фенолкарбоновые кислоты (феруловая, кофейная), 3 неидентифицированных кумарина. В траве сельдерея пахучего содержатся дубильные вещества преимущественно конденсированной группы.

Установлено, что трава сельдерея пахучего содержит органические кислоты: аскорбиновую, лимонную, янтарную, винную, щавелевую, яблочную.

Выделены полисахариды травы сельдерея пахучего (общий выход 17,2\%), среди которых водорастворимых полисахаридов (ВРПС) - 6,3\%.

Анализ выхода экстрактивных веществ с использованием этилового спирта различной концентрации и воды показал, что наибольший выход экстрактивных веществ наблюдается при использовании воды очищенной $(31,5 \%)$ при показателях влажности сырья - 8,55\%, общей золы - 6,37\% и золы, нерастворимой в $10 \%$ хлористоводородной кислоте, $-0,99 \%$.

Исследование фармакологической активности водных извлечений, полученных из травы сельдерея nахучего. Фармакологические исследования проводились на кафедре фармакологии Пятигорского филиала Волгоградского государственного медицинского университета.

Эксперименты были проведены на белых беспородных половозрелых крысах обоего пола линии Wistar, массой 240-290 г и серых мышах обоего пола линии МБА, весом 23-26 г, выращенных в питомнике Пятигорской государственной фармацевтической академии. Животные содержались в стационарных условиях вивария, получали стандартный корм и воду без ограничения. Время исследования - ноябрь. При работе с животными соблюдались методические рекомендации фармакологического государственного комитета. Для статистической обработки результатов использовали программный пакет Microsoft Office Excel 2007. Острую токсичность отвара и настоя травы сельдерея пахучего определяли методом Кёрбера [10, 11].

Отвар и настой из травы сельдерея пахучего вводили в дозах в перерасчете на массу мышей с учетом максимально допустимого количества жидкости, которое можно ввести внутрижелудочно белым мышам - 1,0 мл однократно [11].

Критериями оценки острой токсичности служили картина интоксикации и выживаемость животных. Контрольным животным внутрижелудочно вводили воду в эквивалентном объеме. 
Проведенные в течение двух недель наблюдения за двигательной активностью, наличием судорог, координацией движения, реакцией на раздражители, тонусом скелетной мускулатуры, дыханием, состоянием кожного покрова, шерсти и окраски видимых слизистых оболочек, потреблением воды и пищи, массой тела не выявили заметных отклонений по сравнению с контрольной группой животных (табл. 3).

Расчеты производили по формуле

$$
L D_{50}=L D_{100}-\frac{\sum(d Z)}{n}=42000-0 / 6=42000 \mathrm{мг} / \text { кг }
$$

где $Z$ - показатель разницы между количеством погибших животных при введении двух соседних доз; $d$ - показатель разницы между количеством двух соседних доз; $n$ - количество животных в группе.

Полученные результаты свидетельствуют о том, что при введении отвара из травы сельдерея пахучего в дозе 42000 мг/кг нет гибели мышей, поэтому можно сделать вывод, что $\mathrm{LD}_{50}>42000$ мг/кг.

При введении настоя из травы сельдерея пахучего в дозе 41000 мг/кг падежа животных не было. Следовательно, для настоя сельдерея пахучего $\mathrm{LD}_{50}>41000$ мг/кг (табл. 4).

Таким образом, по классификации токсичности веществ при пероральном введении по К.К. Сидорову отвар и настой травы сельдерея пахучего относятся к веществам VI класса токсичности, т.е. являются относительно безвредными для человека [12].

Таблица 3. Результаты исследования «острой» токсичности отвара травы сельдерея пахучего

\begin{tabular}{|c|c|c|c|c|c|c|c|}
\hline \multirow{2}{*}{ Показатель } & \multicolumn{7}{|c|}{ Дозы, мг/кг } \\
\hline & 37000 & 38000 & 39000 & 40000 & 41000 & & 42000 \\
\hline Выжило & 6 & 6 & 6 & 6 & 6 & & 6 \\
\hline Погибло & 0 & 0 & 0 & 0 & 0 & & 0 \\
\hline$Z$ & & 0 & 0 & 0 & 0 & 0 & \\
\hline$d$ & & 1000 & 1000 & 1000 & 1000 & 1000 & \\
\hline$d Z$ & & 0 & 0 & 0 & 0 & 0 & \\
\hline
\end{tabular}

Таблица 4. Результаты исследования «острой» токсичности настоя травы сельдерея пахучего

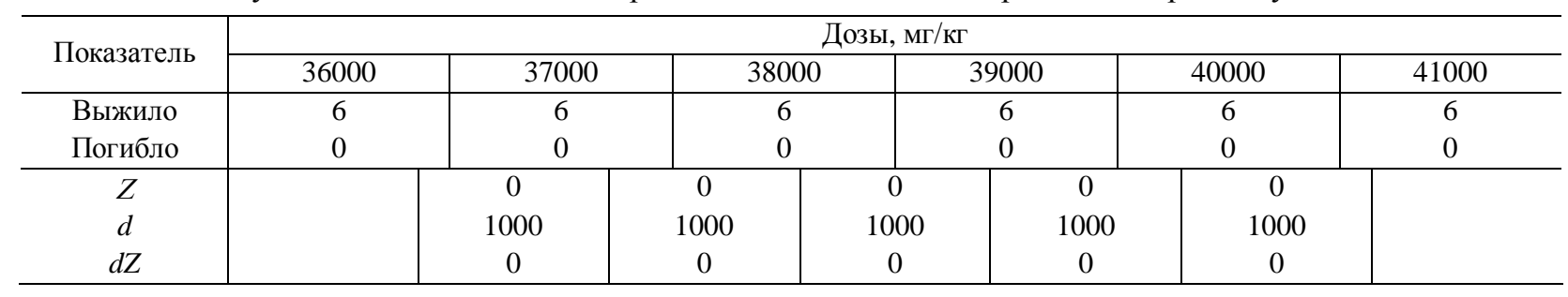

$$
L D_{50}=41000-0 / 6=41000 \mathrm{мг} / \kappa \Gamma .
$$

Диуретическую активность настоя и отвара травы сельдерея пахучего изучали методом Taylor,Tolpiss [10]. Опыт проводили на 24 крысах обоего пола, которых содержали 24 ч до начала эксперимента без пищи и воды. Животных помещали в «обменные» клетки. Мочу собирали в течение 4 ч. Исследуемые объекты вводили однократно внутрижелудочно с помощью зонда из расчета общего объема жидкости 25 мл/кг.

Животные были разделены на четыре группы:

- первой группе вводили настой, приготовленный в соотношении $1: 10$ в дозе 4,0 мл/кг;

- второй группе вводили отвар, приготовленный в соотношении $1: 10$ в дозе 4,0 мл/кг;

- третьей группе вводили препарат сравнения - леспенефрил в дозе 4,0 мл/кг;

- четвертая группа была контрольной и получала воду очищенную в адекватном объеме.

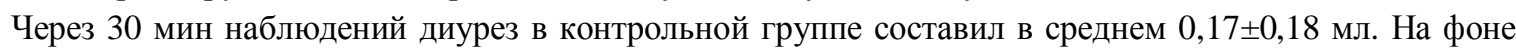

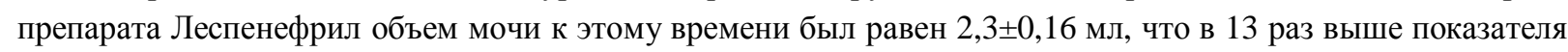
контрольной группы (табл. 5).

Диурез опытных животных, получавших отвар травы сельдерея пахучего, на 30-й мин составил в

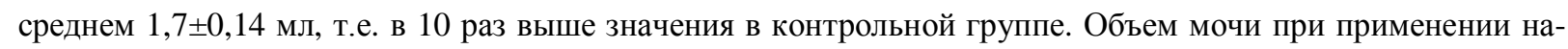
стоя травы сельдерея пахучего в то же время составил 1,47士0,13 мл, что в 8 раз выше показателя контрольной группы.

Спустя 60 мин после введения исследуемых объектов объем мочи на фоне препарата Леспенефрил увеличился на 75\%, на фоне отвара травы сельдерея пахучего на $92 \%$ в сравнении с контролем, а после введения настоя травы сельдерея пахучего количество отделяемой мочи увеличилось на $49 \%$. 
Таблица 5. Влияние водных извлечений из травы сельдерея пахучего на диурез крыс

\begin{tabular}{l|c|c|c|c|c}
\hline \multirow{2}{*}{ Исследуемый объект } & \multicolumn{5}{|c}{ Объем мочи/время, мл/мин } \\
\cline { 2 - 6 } & $30^{\prime}$ & $60^{\prime}$ & $120^{\prime}$ & $180^{\prime}$ & 240 \\
\hline Контроль (вода) & $0,17 \pm 0,18$ & $1,62 \pm 0,47$ & $2,28 \pm 0,47$ & $2,38 \pm 0,49$ & $2,40 \pm 0,50$ \\
Леспенефрил & $2,30 \pm 0,16^{\mathrm{x}}$ & $2,85 \pm 0,24^{\mathrm{x}}$ & $3,70 \pm 0,10^{\mathrm{x}}$ & $3,70 \pm 0,10^{\mathrm{x}}$ & $4,80 \pm 0,19^{\mathrm{x}}$ \\
Отвар травы & $1,70 \pm 0,14^{\mathrm{x \#}}$ & $3,12 \pm 0,27^{\mathrm{x}}$ & $5,20 \pm 0,35^{\mathrm{x}}$ & $5,30 \pm 0,32^{\mathrm{x \#}}$ & $5,30 \pm 0,32^{\mathrm{x}}$ \\
сельдерея пахучего & & & & \\
Настой травы & $1,47 \pm 0,13^{\mathrm{x \#}}$ & $2,42 \pm 0,11$ & $4,14 \pm 0,45^{\mathrm{x}}$ & $4,20 \pm 0,42^{\mathrm{x}}$ & $4,55 \pm 0,42^{\mathrm{x}}$ \\
сельдерея пахучего & & & & & \\
\hline
\end{tabular}

Примечания: ${ }^{\mathrm{x}}$ - изменения достоверны по отношению к контролю, $\mathrm{p}<0,05 ;^{\#}-$ изменения достоверны по отношению к леспенефрилу, $\mathrm{p}<0,05$.

В последующие 3 ч наблюдения диурез опытных животных, получавших Леспенефрил, был в среднем на 70\% выше контрольного показателя, но на 38\% ниже, чем при введении отвара травы сельдерея пахучего, и на 7\% ниже, чем при введении настоя травы сельдерея пахучего.

Итоговый результат (через 4 ч) эксперимента свидетельствует о том, что действие исследуемых объектов достоверно выше контроля в 1,9-2,2 раза. По отношению к препарату сравнения Леспенефрил отвар обладает более выраженным действием. Уже с 60-ой минуты опыта и до конца эксперимента диурез на его фоне был достоверно выше на 10\%. Конечный результат влияния настоя из травы сельдерея пахучего на диурез крыс достоверно ниже показателя действия леспенефрила на 5\%. В сравнительном аспекте лекформ из травы сельдерея пахучего действие отвара на процесс мочеобразования у крыс несколько сильнее (на 15\%), чем эффект настоя; достоверность результатов наблюдали с 60-й минуты опыта.

Таким образом, экспериментально установлено, что отвар и настой травы сельдерея пахучего обладают мягкой диуретической активностью, сопоставимой с действием известного препарата Леспенефрил.

Исследование желчегонной активности отвара и настоя травы сельдерея пахучего. Исследование желчегонной активности отвара и настоя травы сельдерея пахучего проводили на 24 крысах обоего пола. Животные за 12 ч до опыта были лишены пищи и воды. Исследуемые объекты вводили перорально за 3 ч до сбора желчи. Препаратом сравнения служил растительный препарат Холосас. Отвар и настой вводили в дозе 4,0 мл/кг. Дозу препарата Холосас рассчитывали с учетом лечебной дозы для человека, она составила 1,2 мл/кг. Контрольным крысам вводили воду очищенную в сопоставимом объеме (табл. 6).

Через 3 ч после введения отвара и настоя крыс наркотизировали и выводили желчный проток. Сбор желчи проводили через трубку в течение 3 ч, по известной методике [10].

Объем желчи у крыс контрольной группы составил 1,25 мл. Холосас по сравнению с контролем достоверно увеличил отделение желчи на $80 \%$, исследуемый отвар травы сельдерея пахучего - на $30 \%$, а настой из травы сельдерея пахучего - на $37 \%$.

Таким образом, водные извлечения травы сельдерея пахучего обладают мягким желчегонным действием, менее выраженным в сравнении с препаратом Холосас.

Таблица 6. Изучение желчегонной активности отвара и настоя травы сельдерея пахучего

\begin{tabular}{c|c|c|c|c}
\hline Исследуемый объект & $\begin{array}{c}\text { Контроль - } \\
\text { физраствор }\end{array}$ & $\begin{array}{c}\text { Холосас - препарат } \\
\text { сравнения }\end{array}$ & $\begin{array}{c}\text { Отвар травы } \\
\text { сельдерея пахучего }\end{array}$ & $\begin{array}{c}\text { Настой травы } \\
\text { сельдерея пахучего }\end{array}$ \\
\hline Объем желчи, мл & $1,25 \pm 0,16$ & $2,25 \pm 0,05^{\mathrm{x}}$ & $1,63 \pm 0,27$ & $1,72 \pm 0,19$ \\
\hline
\end{tabular}

Примечание: ${ }^{\mathrm{x}}$ - изменения достоверны относительно контроля, $\mathrm{p}<0,05$.

\section{Выводы}

1. В результате изучения надземной части сельдерея пахучего, произрастающего на Северном Кавказе, определено содержание флавоноидов, кумаринов, фенолкарбоновых кислот, дубильных веществ, органических кислот, полисахаридов.

2. Результаты «острого» опыта показали, что $\mathrm{LD}_{50}$ отвара и настоя, полученных из травы сельдерея пахучего, при пероральном применении более 42000 и 41000 мг/кг соответственно.Это позволяет отнести их, по классификации К.К. Сидорова, к веществам VI класса токсичности, т.е. относительно безвредным для человека.

3. Настой и отвар травы сельдерея пахучего в дозе 4 мл/кг крысам оказывают мочегонный эффект, не уступающий диуретическому действию препарата Леспенефрил. Увеличение диуреза, по-видимому, связано с тем, что в исследуемых объектах присутствуют в большом количестве калий, апиол и аспарагин.

4. При введении настоя и отвара травы сельдерея пахучего крысам в дозе 4,0 мл/кг наблюдали мягкое желчегонное действие, превышающее контрольный показатель на 30-37\%, но на 42-50\% слабее эффекта препарата сравнения Холосас. 


\section{Список литературы}

1. Растительные ресурсы СССР: Цветковые растения, их химический состав, использование. Семейства Rutaceae - Elaeagnaceae. Л., 1988. С. 81-83.

2. Пупыкина К.А. Фитохимическое изучение и антиоксидантные свойства некоторых растений, интродуцированных в Республике Башкартостан // Вестник ВГУ, Серия: Химия. Биология. Фармация. 2006. №2. С. 357-360.

3. Бандюкова В.А., Шинкаренко А.Л. Тонкослойная хроматография флавоноидов // Химия природных соединений. 1983. №1. С. 20-24.

4. Бандюкова В.А. Фенолокислоты растений, их эфиры и гликозиды // Химия природных соединений. 1983. №3. C. 263-273.

5. Горбунова Т.А., Даргаева Т.Д. Стандартизация сухого сока каланхоэ // Ресурсоведческое и фитохимическое изучение лекарственной флоры СССР. М., 1991. С. 190-195.

6. Химический анализ лекарственных растений / под ред. Н.И. Гринкевич, Л.Н. Сафронович. М., 1983. 176 с.

7. Государственная фармакопея СССР. Вып. 1: Общие методы анализа. 11-е изд., доп. М., 1987. 336 с.

8. Государственная фармакопея СССР. Вып. 2: Общие методы анализа. Лекарственное растительное сырье. 11-е изд., доп. М., 1989. 440 с.

9. Беликов В.В., Шрайбер М.С. Методы анализа флавоноидных соединений // Фармация. 1970. №1. С. 68-72.

10. Сернов Л. Н., Гацура В.В. Элементы экспериментальной фармакологии. М., 2000. 352 с.

11. Фисенко В.П. Руководство по экспериментальному (доклиническому) изучению новых фармакологических веществ. М., 2000. С. 114-119.

12. Березовская И.В. Классификация химических веществ по параметрам острой токсичности при парентеральных способах введения // Химико-фармацевтический журнал. 2003. №3. С. 32 -34.

Поступило в редакиию 5 мая 2012 г.

После переработки 14 декабря 2012 г.

Pshukova I.V.*, Kuleshova S.A. PHYTOCHEMICAL STUDYING AND ESTIMATION OF PHARMACOLOGICAL ACTIVITY OF WATER EXTRACTION OF HERBA APIUM GRAVEOLENS L.

Pyatigorsk branch of Volgograd State Medical University, pr. Kalinina, 11, Pyatigorsk, 357532 (Russia),

e-mail: daironas@mail.ru

Data on studying of composition of herba of Apium graveolens L. growing in the North Caucasus are resulted, and research of pharmacological activity of its water extraction. It is established that infusion and broth of herba of Apium graveolens L. possess diuretic and choleretic action and are almost nontoxical.

Keywords: celery odorous, Apium graveolens L., biologically active compound.

\section{References}

1. Rastitel'nye resursy SSSR: Tsvetkovye rasteniia, ikh khimicheskii sostav, ispol'zovanie. Semeistva Rutaceae - Elaeagnaceae. [Plant Resources of the USSR: Flowering plants, their chemical composition and utilization. The family Rutaceae - Elaeagnaceae.]. Leningrad, 1988, pp. 81-83. (in Russ.).

2. Pupykina K.A. Vestnik VGU, Seriia: Khimiia. Biologiia. Farmatsiia, 2006, no. 2, pp. 357-360. (in Russ.).

3. Bandiukova V.A., Shinkarenko A.L. Khimiia prirodnykh soedinenii, 1983, no. 1, pp. 20-24. (in Russ.).

4. Bandiukova V.A. Khimiia prirodnykh soedinenii, 1983, no. 3, pp. 263-273. (in Russ.).

5. Gorbunova T.A., Dargaeva T.D. Resursovedcheskoe i fitokhimicheskoe izuchenie lekarstvennoi flory SSSR. [Resursovedcheskoe and phytochemical study of medicinal flora of the USSR.]. Moscow, 1991, pp. 190-195. (in Russ.).

6. Khimicheskii analiz lekarstvennykh rastenii / Ed. N.I. Grinkevich, L.N. Safronovich. [Chemical analysis of medicinal plants / ed. N.I. Grinkevych, L.N. Safronovich.] Moscow, 1983, 176 p. (in Russ.).

7. Gosudarstvennaia farmakopeia SSSR. Vyp. 1: Obshchie metody analiza. 11-e izd., dop. [State Pharmacopoeia of the USSR. Part 1: General methods of analysis. 11th ed.]. Moscow, 1987, 336 p. (in Russ.).

8. Gosudarstvennaia farmakopeia SSSR. Vyp. 2: Obshchie metody analiza. Lekarstvennoe rastitel'noe syr'e. 11-e izd., dop. [State Pharmacopoeia of the USSR. Part 2: General methods of analysis. Herbal drugs. 11th ed.]. Moscow, 1989, 440 p. (in Russ.).

9. Belikov V.V., Shraiber M.S. Farmatsiia, 1970, no. 1, pp. 68-72. (in Russ.).

10. Sernov L. N., Gatsura V.V. Elementy eksperimental'noi farmakologii. [Elements of Experimental Pharmacology]. Moscow, 2000, 352 p. (in Russ.).

11. Fisenko V.P. Rukovodstvo po eksperimental'nomu (doklinicheskomu) izucheniiu novykh farmakologicheskikh veshchestv. [Guidelines for experimental (preclinical) studies of new pharmacological agents.]. Moscow, 2000, pp. 114-119. (in Russ.).

12. Berezovskaia I.V. Khimiko-farmatsevticheskii zhurnal, 2003, no. 3, pp. 32 -34. (in Russ.).

\footnotetext{
* Corresponding author.
} 